\title{
Algunas visiones sobre un mismo ritual: La fiesta de quince-años
}

\author{
Mercedes Palencia Villa, Víctor Gruel*
}

\begin{abstract}
Resumen
En el presente artículo, se describe el ritual de transición de los quinceaños a través de narraciones de sus protagonistas. Se extrajeron estos datos en dos contextos escolares situados en la ciudad de Guadalajara, México, con la finalidad de identificar algunas visiones de un mismo acto festivo.
\end{abstract}

Palabras clave: ritual, adolescencia y proceso de individualización.

\begin{abstract}
The present article there is described the ritual of transition of fifteen years across stories of their protagonists. This information was extracted in two school contexts, placed in the city of Guadalajara, Mexico, with the purpose of identifying some visions of the same festive act.
\end{abstract}

Key words: ritual, adolescence and individualization process.

* Mercedes Palencia Villa: Profesora-Investigadora del Departamento de Ciencias en Educación en la Universidad de Guadalajara, México. Correo electrónico: mercedesp@megared.net.mx

Víctor Gruel: Estudiante Licenciatura en Sociología, en la Universidad de Guadalajara, México. Correo electrónico: victorgruel41@hotmail.com 


\section{Puntos de Partida}

En el tradicional festejo de los quince-años, la chica viste un atuendo que trata de representar una princesa de las cortes europeas y, entre más lujosa y espectacular sea la fiesta, se ostentará una mejor muestra de poder económico y de una capacidad de ascenso social durante el instante de la celebración. La ceremonia religiosa forma parte de este ritual y el sermón del párroco alude y exalta este proceso de transición de la infancia a la adultez, indicando las pautas morales que debe practicar esta niña que se transforma en mujer. En la mayoría de los sermones, se alienta a las jóvenes a permanecer vírgenes hasta que contraigan matrimonio, a obedecer a sus padres y, últimamente, se incluyen algunas tentaciones mundanas como el sexo, las drogas y el pecado carnal. El discurso se actualiza subrayando la importancia del estudio y la preparación para enfrentar un futuro incierto.

Con el tiempo, este ritual ha cambiado según el contexto social; en algunos sectores urbanos e inclusive rurales, dicha tradición aún se conserva, pero en ocasiones deja a un lado los valses vieneses y se comienzan a utilizar melodías instrumentales de ritmo lento y cadencioso, que se bailan de manera pausada, con movimientos laterales y livianos giros. Se busca la novedad, la moda y las melodías que están sonando en ese momento en la radio. Incluso, en últimas fechas, ya no se considera que solo se pueda utilizar música instrumental, pues también se han comenzado a usar melodías populares cantadas.

En un documental situado en el 2002, filmado en pleno siglo XXI titulado: XV en Zaachila ${ }^{2}$, un pequeño poblado indígena de Oaxaca, se presenta todo el proceso de preparación de dicha celebración, la cual se inicia seis meses antes. Estos preparativos consisten en elaborar comida para atender a 850 invitados, tener

2 Este documental titulado "XV en Zaachila" se presentó en el festival "AMBULANTE" 2006, los primeros tres meses del presente año, con la finalidad de dar a conocer este género a la mayor parte de la población que asiste al cine comercial. Dirección: Rigoberto Perezcano, Productora: 13 lunas, SEP, CONACULTA (fuente: catálogo $1^{\circ}$ Festival Internacional de Cine en Morelia). 
listo el salón donde se llevará a cabo y los frecuentes ensayos para el vals con catorce chambelanes, quienes acompañarán a la quinceañera durante toda la celebración. Como la celebración requiere de una cantidad de dinero considerable, este se logra obtener con el ahorro familiar desde el nacimiento de la hija. Esto se debe en gran medida a que el prestigio del progenitor se sustenta en el grado de organización de dicha fiesta.

Esta cinta fílmica se compone de entrevistas a los protagonistas, en donde narran el sentido que le atribuyen a dicha celebración. Los padrinos adquieren un papel primordial, y esta elección obedece a los recursos económicos que poseen, con la finalidad de que cooperen en la compra de todos los accesorios de la festejada. El compadrazgo es importante a fin de establecer redes vinculantes que permitan a los progenitores acceder a ciertos beneficios de influencia, para diferentes fines como un trabajo, cooperar en la educación de la ahijada, o en alargar la red familiar hacia otras comunidades en la zona.

Este ritual, cómo señala Emma Ruiz (2001:207), remite a exigencias sociales relativas al cortejo, roles de género y las relaciones con los adultos. No obstante, señala la autora que este tipo de celebración no da ningún mensaje en cuanto a los lugares que pudieran ocupar las mujeres en el ámbito público. Por el contrario, el ritual parece sugerir actitudes pasivas a las chicas, puestas a disposición de los varones jóvenes y colocando su virginidad bajo la custodia de figuras simbólicamente investidas de autoridad. Sin embargo, este discurso entra en contradicción con otros que emergen en el papel de las mujeres.

En este sentido, las entrevistas realizadas a la progenitora de la quinceañera y a una vecina de la comunidad expresan tales contradicciones. Su madre le desea a su hija un futuro inmediato profesional y se aleja de la idea tradicional de que la chica se encuentra en la edad oportuna para contraer matrimonio, como le fue enseñado por sus padres. Este discurso influye en la quinceañera, quien desea concluir la carrera de psicología. 
Por su parte, la vecina expresa que se han dado casos, en los últimos años en el pueblo, en que algunas jóvenes, después de esta celebración, huyen con el novio, situación que provoca una reacción de desprestigio hacia los padres de la chica por parte de la población. Lo que representa que todo el esfuerzo invertido por la familia para lograr un status se revierte cuando la chica escapa con su pareja. Para la familia, resulta vergonzoso porque el ritual contiene una serie de símbolos en los que la virginidad de la quinceañera es protegida por los padres; como señala Emma Ruiz: "el ramo es símbolo de virginidad, es puesto bajo la custodia de un padre y una madre, internalizados en los que se cree y que están investidos de autoridad... ahora los padres no podrán estar tan presentes en la vida de la niña convertida en mujer y se apela a lo simbólico para promover cierto orden social en torno a la vida sexual" (ibid: 215).

Lo anterior nos conduce a comprender de qué manera esta celebración tiene implicaciones sociales importantes en dichas comunidades, pero en las grandes urbes adquiere diferentes significados. En el presente artículo, se tratará de responder la siguiente pregunta: ¿Qué implicaciones tiene este ritual de transición en diferentes contextos sociales? Para este objetivo, retomo algunas narraciones extraídas de los grupos de discusión, realizados en dos contextos escolares opuestos (una escuela pública, y una elitista) ${ }^{3}$ en donde este tema surgió entre las chicas y resultó un material empírico interesante que decidí utilizar para la elaboración del presente artículo.

\section{La adolescencia: un discurso que clasifica}

La palabra Adolescente significa persona que está en el periodo de crecimiento que sigue a la niñez, viene del latín adolescentem,

3 Los grupos de discusión tuvieron como finalidad realizar una indagación sobre las actividades del tiempo libre y sus intereses más importantes en la sociabilidad con sus pares. Extraigo parte de este material empírico para realizar el presente artículo, con la finalidad de discutir el concepto de adolescencia y su impacto en los estudiantes de secundaria (en México, cursan este nivel educativo cuando las chicas cumplen 15 años. Por lo tanto, resultó un acontecimiento importante, pero con diferentes significados en cada contexto escolar). 
acusativo de adolescens (radical adolescent) que está creciendo, participio activo de adoleceré: "crecer, desarrollarse, de ad: "hacia" Gómez de Silva (1988:33). Sin embargo, la edad biológica no siempre ha sido una manera de clasificar las etapas de la vida, pues Philippe Ariés (1987:196) nos muestra cómo en la Edad Media no se representaba la infancia y menos todavía al adolescente. La infancia se reducía al período de fragilidad, cuando se creía que el niño no podía valerse por sí mismo, de tal forma que se convertía en adulto sin pasar por las etapas de juventud, las cuales no existían antes de la Edad Media y que son esenciales actualmente en las sociedades desarrolladas.

La presencia del niño en la familia y en la sociedad era tan breve e insignificante que no había tiempo para grabarlo en la memoria familiar. Para Ariés, el primer prototipo del adolescente moderno es el Sigfrido ${ }^{4}$ de Wagner, ya que este personaje operístico expresa por primera vez la mezcla de pureza provisional, fuerza física, sed de aventuras y alegría de vivir, que hará del adolescente el héroe del siglo XX, el cual es llamado "siglo de la adolescencia". Y los colegios europeos del Siglo XVIII, antecedentes históricos del actual sistema de enseñanza secundaria, son instituciones específicas que surgen para "tratar" con adolescentes. De ahí la importancia de ubicarnos en dicho contexto escolar para extraer las narraciones de las chicas.

A pesar de ello, este término se interpreta como problema de la juventud y, según Passerni (1996:420), adquiere una importancia significativa con la publicación, en 1904, de Adolescence, obra del psicólogo Stanley Hall, que anuncia el descubrimiento de los adolescentes americanos. Este autor atribuye a esta fase de la vida

4 Sigfrido héroe principal de las mitologías germánica y escandinava, que ha inspirado a Wagner el famoso drama musical de su nombre (1876). Pérez- Rioja señala: "que es símbolo de amor incestuoso (es hijo de los hermanos Sigmundo y Siglinda) está destinado a liberar a Brunilda, la virgen guerrera, a la que su padre Wotan durmió rodeándola de llamas para que nadie pudiera acercarse a ella. También le cabe a Sigfrido la misión de matar al gigante Fafner y de conquistar el famoso tesoro de los Nibelungos" (1971). 
cualidades anti-éticas tomadas de Rousseau, ${ }^{5}$ como son: la hiperactividad, egocentrismo y locura infantil. Dicha idea conduce a decir que una estrategia para esta etapa de la vida es el adiestramiento militar, como la actividad que mejor podía desarrollar las potencialidades de los adolescentes. Hall no hacía más que racionalizar la extensión de la juventud como etapa de semi-dependencia en los países occidentales, proceso que tuvo lugar a finales del siglo XIX en relación con la expulsión de los jóvenes del mercado de trabajo, a la extensión de la escolaridad obligatoria y del servicio militar, a la nuclearización de la familia y al surgimiento de entidades orientadas específicamente a la juventud. En este sentido, Passerni (ibid: 425) señala que, durante todo el siglo, el debate sobre la adolescencia y juventud en los Estados Unidos se movía en dos polos: por un lado, la exigencia de garantizar la libertad y posibilidad de autogobierno y, por otro, la de uniformar, colectivizar y restituir a la sociedad las iniciativas creativas de los jóvenes.

Esta idea de "peligro" se considera también en el siglo XIX en occidente, en donde la adolescencia es sinónimo de riesgo. Pero esta discusión toma mayor relevancia en el siglo XX, cuando Margaret Mead inició sus trabajos de campo en Samoa en 19256,

5 En el occidente, Rousseau (1979), en el libro IV de Emilio, influye de manera significativa en las maneras de educar a la niñez y sobre todo a los adolescentes que se encuentran en una edad peligrosa, ya que las fuerzas subyacentes de la sexualidad tienen como resultado "el peligro" de la masturbación. De esta manera, Rousseau sugirió desarrollar, en los adolescentes, prácticas pedagógicas que se centraran en la lectura y el deporte, con el fin de propiciar un freno a la sexualidad anárquica y a sus pulsiones negativas. En otras palabras, resultaba imprescindible ejercer sobre ellos un fuerte control social que se sostuviera a través de una domesticación social del adolescente.

6 Margaret Mead (1985) en sus investigaciones en las islas del pacífico de Nueva Guinea, en la década de los años veinte, señala cómo la pubertad significa para las niñas el término de los juegos y esta etapa biológica es celebrada mediante tres fiestas públicas. Cuando la niña tiene sus primeras menstruaciones, el padre o tutor le arroja al agua gran cantidad de nueces de coco y se inicia el proceso para comprometer a la chica con algún prometido. Desde el momento de la pubertad hasta el del matrimonio, las muchachas no tienen participación activa en la vida de la aldea; se les concede menos libertad pero no más importancia. Para los varones, se efectúa la ceremonia de perforación de orejas, la que tiene lugar entre los doce y los dieciséis años. Las fiestas de este género no están ligadas a ningún tabú, ni implican importantes compromisos económicos, sino se traducen sólo como una bendición familiar. El joven continúa haciendo su vida anterior, célibe aun, libre de deberes económicos y sociales; pero la sombra de su próximo matrimonio se inicia a partir de la pubertad. 
pues estas ideas estaban muy en boga entre los educadores norteamericanos. De hecho, nos señala Feixa (1996:321) que el estudio de Mead era un intento de refutar las teorías de Hall, mostrando que no todas las culturas de la adolescencia podían verse como fase de "tempestad y estímulo", generalizada a partir del caso de los jóvenes en Norteamérica.

Muchos años después, Freeman, citado por Feixa (Ibíd.: 426), pondría en cuestión las aserciones básicas de Mead, acusándola de ofrecer una imagen demasiado idílica de la cultura samoana, condicionada por sus propios presupuestos ideológicos y por las limitaciones del trabajo de campo (fragmentario y con un precario conocimiento de la lengua). Para Freeman, las características de la adolescencia en Samoa eran diametralmente opuestas a las señaladas por Mead: agresividad sexual, dependencia familiar, jerarquización según el rango, castigos físicos, violencia y valoración de la virginidad eran rasgos centrales. Asimismo, Freeman iba más allá al postular la importancia de los factores biológicos supuestamente ignorados por Mead?

Los factores biológicos se manifiestan en la pubertad y esta es una experiencia universal, considerándose el inicio de la adolescencia. Sin embargo, a lo largo de estas décadas, se ha venido produciendo un adelanto gradual del inicio de la pubertad, de tal forma que algunos de los primeros cambios físicos comienzan a edades tan tempranas como los 8 años. Las mejores condiciones de vida, pero también la influencia de agentes contaminantes sobre el sistema endocrino pueden tener la responsabilidad de este adelanto. Según señala Alfredo Oliva (2003: 375), diversos estudios han encontrado relación entre la pubertad precoz y el uso de pesticidas en la agricultura intensiva y de hormonas en la alimentación y engorde de ganado (Heman-Giddens et al., 1997).

7 Es por ello que señala Feixa que, en el libro de Freeman, ha sido considerada la querella más importante de la antropología contemporánea, en el que intervinieron las figuras más representativas de la disciplina en Norteamérica (Clifford, Harris, Marcus y Schepeer-Hygues). 
Por lo tanto, la pubertad se inicia antes que en generaciones anteriores, lo cual se suma al contexto cultural, en donde la sexualidad se propicia en todos los medios de comunicación, y, cuando las chicas festejan sus quince-años, la celebración se torna más bien tradicional que iniciática. Desde el punto de vista psicoanalítico, Emma Ruiz (ibid: 191) señala que los cambios fisiológicos de la pubertad dan nuevo ímpetu a los impulsos genitales que habían sido reprimidos y ponen a las chicas y los chicos en crisis, y los introducen en una fase de intensa movilidad emocional: la adolescencia. Asimismo, se considera la adolescencia como una segunda oportunidad para la reestructuración de la personalidad y la resolución de conflictos fundamentales. Para esta autora, los rituales de iniciación en sociedades tradicionales ayudan a los jóvenes a iniciar esta etapa de mayor adaptación.

Sin embargo, hoy en día, en las sociedades modernas, el paso de adolescente a mujer se da en el ámbito de un mayor espectro de posibilidades: postergación del matrimonio para el desarrollo profesional o de otras formas de vida social, opción por la maternidad o decisión de no tener hijos, lo que conduce a una variedad de grupos de referencia que tienen las jóvenes; esto tiene como resultado sociedades heterogéneas. Dichos discursos alternativos conducen a que este ritual pierda su sentido original, aunque sí mantenga en la memoria colectiva la idea de que cumplir 15 años constituye un aniversario especial. Por lo cual, resulta interesante rescatar dichos discursos a través del análisis del contexto y sus implicaciones sociales.

\section{Las quinceañeras en una escuela pública}

La escuela pública se ubica en una colonia con una mayor densidad de población en edad escolar: en términos relativos, casi un $20 \%$ (de 6 a 14 años) y solo el $4 \%$ más de 65 años; solo un poco más del 6\% tiene más de 60 años. La población de 6 a 14 años que asiste a la escuela es un $92.79 \%$ y el grado promedio de escolaridad es de 7.2 grados y casi la mitad de la población mayor de 15 años no tiene instrucción posprimaria. 
Ubicada en una zona urbana que bien puede ser un límite municipal entre Guadalajara y Tonalá, la escuela secundaría ocupa un gran espacio de la colonia. Pareciera ser una fortaleza medieval rodeada de centros de videojuegos (preferentemente masculinos), tiendas de abarrotes y casas. Los graffitis sobre los muros son motivo tanto de una resistencia juvenil como parte de los proyectos estudiantiles de renovar escuela y comunidad, pues curiosamente solo una puerta mantiene la distancia entre estas dos realidades. Las diferencias estriban en que, mientras los alumnos pretenden ampliar los dominios del barrio, el personal procura reiterar su carácter educativo.

En este contexto escolar, observamos a las chicas en los recesos escolares, con revistas de modas y buscando los mejores diseños para tal evento; asistir a las fiestas de quince años resulta ser una cita frecuente, pero el ritual de los chambelanes y el vals es una discusión que con frecuencia se oye hablar entre ellas. Algunas prefieren bailes modernos y otras el vals, pero, al fin de cuentas, el ritual se realiza.

En los grupos de discusión, Vanesa expresó la importancia que le atribuye su familia a dicho evento; muestra de ello es que sus padres pospusieron el festejo de su aniversario al periodo de vacaciones, con la finalidad de que sus tíos, que viven en Estados Unidos, puedan asistir a la fiesta. En la familia de Vanesa, esta fiesta es tradicional y se lleva a cabo con o sin el consentimiento de las hijas de familia, como señala ella:

Vanesa: A mi hermana se lo festejaron en Estados Unidos; yo no pude ir... Solo me mandaron las fotos -como ella vive allá se la llevó mi tío a trabajar- haga de cuenta... Que mi tía no le tomó opinión a ella, no le preguntó sí quería, sino que se la hizo, le escogió mi tía al chambelán, o sea mi tía se lo escogió todo a ella, mi hermana no opinó nada.

Al preguntarle qué opinaba nos respondió: a mí que me 
dejaran escoger al chambelán, el vals no sé.... pero yo escogerlo... (Risas...).

Vanesa no se cuestiona la fiesta, sino la posibilidad de elegir al chico y algunos detalles para tal evento, ya que es obligatorio al interior de su familia. Ella pelea el derecho a decidir, en una ambivalencia entre tradición y modernidad en la que viven las generaciones actuales.

En la ceremonia de los quince-años, el padre tiene un papel fundamental al bailar con ella el vals y aceptar simbólicamente que otros bailen con su hija. Este papel del progenitor se repite en el ritual del matrimonio religioso, pues el padre entrega a la chica en el altar y, con su anuencia, ella contrae matrimonio. Esta situación patriarcal se sustenta en la aportación de los costos de la fiesta y el padre juega un rol en estos dos rituales.

Esta relación la establece Mary, quien expresó sentirse desilusionada porque a ella no le festejaron sus quince años, sino solamente una comidita pequeña con sus familiares y la razón que les dieron sus padres fue que resultaba una injusticia festejarle a ella, siendo que a su hermana mayor no lo hicieron y, consecuentemente, no podían hacer diferencias entre ellas. No obstante, Mary señala que, a pesar de ello, mantiene la esperanza de que, cuando contraiga matrimonio, sus padres no podrán negarle vivir la satisfacción de ser una princesa de cuentos por un día, como lo dice a continuación:

Mary: no sé, pero como no me hicieron fiesta de quince
años, cuando yo me case, sí quiero que me hagan una
fiesta grandota, elegante y que luzca... con mi vestido
elegante y bonito... lo que no me hicieron en mis quince
que me lo hagan cuando me case...

Evidentemente, la crisis económica conduce a los padres a festejar de diferentes maneras este aniversario, lo cual permite a las chicas buscar nuevas opciones para festejarlo, como lo dice Zamira: 
Yo fui al mar con mis amigos, yo sola, ya que no había mucho dinero para una fiesta.

Para Zamira, cumplir quince-años y no tener dinero le permitió lograr la anuencia de sus padres para ir con sus amigos al mar; fue de campamento, ya que no tenía recursos para otro tipo de hospedaje, pero ese fue su único aliciente, ya que comentó la nostalgia de no tener su fiesta tradicional; pero la razón gira alrededor de su relación con su padre, según lo que ella misma narró:

En los quince años de mi mejor amiga, salí de su madrina y lo único que envidié fue que ella sí pudo bailar con su papá. Es lo que a mí me gustaría bailar con mi papá, porque mi papá no convive mucho conmigo... siempre andamos en riñas...no la llevamos bien... en mi casa estoy muy triste y aburrida... si mi papá fuera otra persona... cuando escucho música me dice: "apaga esa chingadera"... "pinche música loca..."

Zamira vive situaciones contradictorias al interior de su familia; por una parte, desea encontrar nuevos modelos de identificación que le den seguridad en la búsqueda de sus propias formas de ser mujer y, por otra, es capaz de renunciar a ellos, con tal de encontrar, al interior de la familia, un equilibrio afectivo. La narración de Zamira hizo eco en Andrea de la siguiente manera:

Andrea: yo pienso lo mismo que Zamira. La tradición de bailar con tu papá es muy bonita, a mí también me gustaría bailar con él, pero él no vive con nosotros y se fue... (comienza a llorar)... mi mamá habla mal de él y no le gusta que hablemos de él... pero a mí me hubiera gustado que, en mis quince años, bailara conmigo.

Como se manifiesta en las narraciones anteriores, los quince años resultan ser un evento que responde a la tradición familiar y que, en algunas chicas, adquiere mayor relevancia. No obstante, este énfasis en el ritual de cumplir los quince años, conlleva una 
serie de elementos subjetivos del imaginario femenino y paralelamente concluyen un nivel educativo que las conduce a un cambio a corto plazo; para algunas, será su último grado escolar y, para otras, se inicia la incorporación a un nuevo nivel educativo. Todos estos cambios de alguna manera las conducen a un ritual de transición que ya no se concibe de la infancia a la adultez, sino a una etapa neutra, en donde la independencia económica, la conclusión de una carrera profesional o casarse, cada vez más, son proyectos de vida diferidos, produciendo una adolescencia alargada.

\section{Las quinceañeras en una escuela elitista}

La escuela elitista se encuentra ubicada en una colonia céntrica (entre centros comerciales) de la ciudad de Guadalajara en donde ninguna de las estudiantes tiene su vivienda; sería más bien un punto intermedio en sus trayectorias urbanas. Entonces, para fines de contextualización, dispondremos de los siguientes datos acerca de los alumnos de tercer año: el 31\% tiene 15 años y, de esa población, el 63\% son chicas (un total de 12). De la escolaridad de los padres, más de la mitad tienen una enseñaza profesional. El 31\% de las madres y el 37\% de los padres tienen estudios de postgrado.

El inmueble no obedece a la infraestructura tradicional de una escuela secundaria, sino que es una casa bastante grande con habitaciones acondicionadas para la tarea escolar. Lo anterior permite la libertad de tránsito desde el patio (con piscina) hasta los pasillos y escaleras. Siendo una escuela tan pequeña, tan solo puede albergar a una población estudiantil reducida, lo cual facilita el pleno reconocimiento de los rostros de quienes asisten ahí, desde el personal docente hasta los alumnos, pasando por la intendencia. En pocas palabras, todos se conocen. Aquella jerga respetuosa que aún se utiliza en las escuelas tradicionales es sustituida por una confianza que tolera tuteos y nombres de pila, sin orden de jerarquías. Esta aparente libertad se traslada hasta al cuerpo: cada 
cual puede llevar la ropa y el corte de cabello qué más le convenga, al contrario de la escuela pública donde la existencia del uniforme permite precisamente controlar el acceso a la Institución.

En este contexto escolar, se permite y se resalta la libre expresión individual a través del cuerpo, merced al hecho de haber dejado de ser un blanco de poder disciplinario. De este modo, las formas de resistencia del alumnado no se manifiestan a través del cuerpo, sino a través del discurso. Usar perforaciones, usar determinada ropa, traer un teléfono celular han dejado de ser una demanda por la cual apelar contra las normas institucionalizadas. La fundadora es de profesión psicoanalista, lo que le ha permitido profundizar sobre las problemáticas por las que atraviesan los jóvenes en la época actual. Estas inquietudes la condujeron a abrir una escuela centrada en el discurso de la adolescencia. Es por ello que esta escuela centra su atención en tanto que adolescentes antes que jóvenes, y no piensan incorporar otros niveles educativos.

Para las chicas que asisten a esta escuela, los quince-años es una tradición que debe ser cambiada; pasar de la formalidad a la informalidad. Esta última consiste en que la quince-añera lleve un vestido no especial; si es informal es mejor. El vals lo consideran ridículo. Una de las chicas a quien le festejaron sus quince-años fue interrogada: ¿Bailaste el vals con tu papá? Nos respondió:

Paulina: No. Bailé banda ${ }^{8}$ (risas). [...] No. Quería bailar otra cosa y por eso bailé banda con mi papá, con mis tíos y con mis primos.

8 El género de banda en México es representativo del Estado de Sinaloa, asociado la mayor parte del tiempo a actos festivos y al folclore regional, es un tipo de música dispuesto para el baile. El tipo de instrumentos utilizados son esencialmente de viento (trombones, clarinetes, trompetas y trombones) acompañado por algunos elementos de percusión, denominados "tamboras". Su lírica gira en torno a situaciones de duelo amoroso («pena tras pena, son las que destrozan mi vida») o metáforas naturalistas («árboles de la barranca, porqué no han enverdecido»). El gusto por la música de "banda" se ha generalizado a todo el país e incluso ha trascendido fronteras con la gira europea de Banda el Recodo, siendo una de las bandas más representativas de está expresión cultural 
Entrevistador: ¿Pero sí será importante bailar con tu papá?

Paulina: Pues me daba igual, la verdad.

Resulta interesante que, para Paulina, el vals no tenga la solemnidad que le atribuyen las otras chicas. Para ella, el género de banda rompe el esquema tradicional del vals $y$, si baila con su padre o primos o tíos, es igual.

Entrevistador: ¿Cómo fue tu vestido o tu...?

Paulina: Ay, con una falda, una blusa...

(Varias chicas al unísono: Informal).

Entrevistador: ¿Para alguien es importante eso?

Chica 2: Por ejemplo, haz de cuenta, si haces tu fiesta si es muy importante bailar con tu papá, porque pues... Entrevistador:¿Aunque sea informal la fiesta?

Chica 2: No, pues no. Si es una reunión, no. Pero así fiesta peque... chiquita, pues no tanto. Pero si es una fiesta grande, así, con todo el mundo, y que se da el vals, sí es muy importante bailar con tu papá.

Entrevistador: ¿Por qué?

Chica 2: Pues porque es la persona más cercana a ti... bueno, se supone. Con la que estás, con la que más confías. Creo que es importante.

La chica 2 atribuye importancia al menos que se baile en una fiesta grande en donde los rituales se deben de mantener. Sin embargo, una de ellas le da un sentido práctico al baile: depende si el padre sabe bailar, lo cual rompe todo simbolismo que conduzca a la sublimación del acto de bailar con su padre, como lo refirió de la siguiente manera:

Chica 7: Es que depende de qué papel le des a tu papá, hay personas que creen que el papá no es apto para bailar. O la verdad si dices, "Ay, viva, mi papá, sí va a bailar". 
El hecho de que las chicas manifiesten cierto rechazo a esta celebración puede estar relacionado con lo que señala Emma Ruiz: "podría tener la carga simbólica de haber llegado el momento de abrirse a horizontes más amplios que el de la familia y comunidad de pertenencia" (2001:221). Como en el caso de Laura, quien afirmó lo siguiente:

Entrevistador: ¿Tú no quisiste quince-años?

Laura: no, me fui de viaje.

Entrevistador: ¿Dónde?

Laura: A Europa.

Paulina: Yo también preferiría eso.

En el anterior diálogo, Paulina -quién sí festejó sus quinceaños- coincide con su compañera en buscar nuevos marcos de referencia para un mismo ritual. Este también ha tenido matices actuales con respecto a la importancia que se le atribuye a mejorar el cuerpo, cuestión que, en la sociedad actual, cobra mayor importancia, identificándose con modelos extremadamente delgadas, con senos artificiales. Una de las chicas expresó que su madre le quería regalar, de quince-años, que se operara la nariz y ella respondió ante tal petición:

Entrevistador: ¿A ti, que te propusieron?

Chica con aspecto Hindú: Pues es que mi mamá desde chiquita, no sé que le pasó, un día le dieron un balonazo y le quedó la nariz chueca y se la operó, y a mí me dijo, igual mi tía cada vez que me ve me dice: "Ay, que fea nariz tienes". Y llega... Mi mamá me dijo un día: "No pues, de quince-años te voy a regalar el dinero para que te operes la nariz". Y yo le dije: "A mí me gusta mi nariz". O sea, aunque esté fea, o qué sé yo, pues a mí me gusta, a mí sí me sirve. Porque a ella se la dejaron mal, entonces a diario anda renegando de "Ay, mi nariz", no sé qué... Entonces...

Chica 2: Pásale el dinero a tú mamá... 
(Todas ríen).

Chica con aspecto Hindú: Entonces yo le dije a mi mamá: "A mí, la verdad, mí nariz sí funciona y es importante que funcione y no que se vea bonita". No es algo que me afecte de "Ay, mi nariz está fea".

Esta libre elección se ha trasladado al cuerpo, el cual es visto como algo que debe ser procesado, manipulado y sometido a través de una inversión financiera. En las familias, la belleza obtenida por medios quirúrgicos se transmite de padres a hijos, igual que la afición por el consumo de bienes de lujo. Su madre transmite a su hija que su cuerpo es un objeto moldeable, plástico, que debería construir de acuerdo a la belleza establecida: todo cuanto se requiere transformar un cuerpo es el dinero necesario para comprar uno nuevo. Sin embargo, el cuerpo sigue presente, en el imaginario de Laura, no como objeto de un diseño, sino como una funcionalidad que le permita acceso a la salud.

Asimismo, las anteriores discusiones nos conducen a evidenciar el proceso de individualización de la chica que se convierte en el proyecto de futuro; ser joven en la actualidad es la lucha por configurar su propia vida (Beck; 2001:121). La vida propia se convierte en un problema cotidiano de acción. El individualismo trae consigo que los sujetos ya no se conformen con heredar principios morales establecidos, sino que quieran tomar parte activa en su transformación.

Esta autodeterminación, que Giddens (1995:147) señala como "política de vida", ha influido en todas las clases sociales y ha cambiado quizá a las mujeres más que a los hombres, propiciando la liberación de papeles sexuales tradicionales, la libertad de la plenitud sexual, la libre elección de estilos de vida y de profesión. Es una característica de la modernidad que la autorrealización sea esencial para la auto-identidad y reflexionar sobre nuestra propia acción que, en las jóvenes, se refleja en el siguiente discurso:

Entrevistador: ¿Ustedes creen que, por su apariencia, 
podemos clasificar un tipo de jóvenes?

Chica 2: Yo creo que todos somos víctimas de la moda. Si se está usando falda cortita, falda larga. Y aunque no quieras, pues, es lo que se vende y es lo que vas a comprar. Pues, estamos muy influenciados por la mercadotecnia gringa y pues aparte como que... bueno, en lo personal, con la gente que yo conozco sí se viste así. Pero, si hay gente que se viste, no sé, que tenga sus gustos diferentes o que se viste con ropa indígena. Y siempre la voltean a ver raro, es cómo “Qué le pasa? ¿Porqué se viste así?” Tenemos algo a seguir, un ejemplar que es la moda gringa. Peor pues, en lo personal, yo creo que a todos nos importa, y el vernos bien y ser fashion y todo eso.

En esta narración, se manifiesta una política de vida en la cual los actores son capaces de decidir las condiciones de su propia acción; es una conciencia que tiene forma discursiva (Giddens; 2003:394). Situación que no puede emanciparse al ser considerada una acción que se encuentra enclavada en unas redes de identificación mutua, en la que se congregan en redes vinculantes que les propician una identidad. En este sentido, los discursos alternativos los conducen, si bien a desarrollar una conciencia discursiva, también a buscar nuevas formas de identificación, aunque sean frágiles o momentáneas. Es decir, en el siglo XXI, el discurso de la adolescencia forma parte del lenguaje de identificación; para los más jóvenes, la escuela; los departamentos de modas, para adolescentes; los medios de comunicación, etc. Identificar a un grupo de la población en esta categoría y nombrarse a sí mismo adolescentes no solo guía sino que estimula una práctica, como lo señala la siguiente narración:

Chica 4: También entre los adolescentes hay muchos estilos; los usamos para demostrar nuestras ideas, ¿no?, y lo que nos gusta. Para expresar lo que te gusta. O sea, cada quien tiene su estilo. $Y$ por eso digo que no podemos... en personalidad no puedes definir a una persona 
si es enojona, tranquila, por la ropa, pero sí puedes ver sus gustos, sus ideas, lo que piensa. Es una forma de expresarte.

Anónima: Sí, como todo.

De esta manera, la moda identifica una serie de códigos que las jóvenes descifran en la cotidianeidad; que clasifica y fragmenta a las redes vinculantes. Es por ello que habría que preguntarnos: ¿Cómo puede subsistir la tradición de los quince-años en diferentes imaginarios colectivos, en una sociedad en donde se configuran diversas identidades?

\section{Reflexiones finales}

Los quince-años resultan ser un ritual que conduce a las jóvenes a diversos marcos de referencia y, paradójicamente para algunas chicas con recursos económicos y padres liberales, es el pretexto oportuno para viajar con el fin de conocer otros contextos culturales y contrastar sus propias concepciones.

Para otras, una gran fiesta informal les permite transformar los códigos, con el fin de poner a prueba el proceso de individualización, desafían el vals a través de otro tipo de música menos solemne y bailan con su padre a condición de que él tenga la habilidad para hacerlo. En este contexto, la imagen paterna deja de ser imprescindible para el rito de transición y la transformación de símbolos, el cual tiene un impacto en el imaginario femenino. Estas prácticas nos manifiestan que el discurso feminista es un discurso alternativo que circula en la cotidianeidad de las mujeres y ha dejado de ser un interés de "elites intelectuales" o "militantes radicales", y se convierte en una alternativa discursiva que compite contra otras formas de enunciación más tradicionales para conseguir la legitimidad de su estilo de vida.

A pesar de que en algunas zonas rurales, por el contrario, los rituales de la fiesta se conservan, los códigos en las comunidades se vuelven herméticos y esto transciende en la percepción de la 
sexualidad femenina, se cuelan discursos alternativos que conducen a las madres a desearles a sus hijas proyectos de vida que las conduzcan a una independencia económica, como es la profesión y el trabajo remunerado antes de contraer matrimonio.

La escuela pública de donde extraje las narraciones que aquí analizo pertenece a una zona marginada de la zona metropolitana de Guadalajara; evidentemente, es un lugar poblado por familias que emigran a la ciudad de zonas rurales con el fin de lograr mejorar sus condiciones económicas. Esto las conduce a una hibridación cultural que van apropiando poco a poco de las metrópolis empobrecidas; estas condiciones las impulsan a mantener sus tradiciones $\mathrm{y}$, una de ellas, es la fiesta de quince-años. Las chicas también retoman formas de individualización al exigir el derecho de elegir a sus chambelanes, situación que propicia una nueva forma de apropiarse de su aniversario. Es posible que interioricen elementos simbólicos de un imaginario femenino que, sin duda, entra en contradicción con la segunda modernidad.

Presentar esta ambivalencia discursiva que hemos encontrado en la ciudad de Guadalajara no es para mostrarnos en una perspectiva ritualista del acontecimiento. Se trató aquí de identificar las narraciones susceptibles de convertirse en un discurso que sea tanto una respuesta al entorno como una descripción del mismo. Las modificaciones estructurales que se van suscitando a lo largo del tiempo están sujetas siempre a la acción individual. Por eso, el énfasis en el ritual de quince-años, pues coloca la acción de las chicas en una posición pertinente para intervenir en las representaciones en torno a su propia sexualidad y a la institución familiar. Una autodeterminación para implicarse en un acontecimiento definitorio para la propia vida. 


\section{Bibliografía consultada}

Aries Philippe (1987). El niño y la vida familiar en el antiguo régimen. Editorial Taurus, Madrid.

Beck / Gernsheim (2001). Individualization. Sage Publications, London Thousand Oaks y Nueva Delhi.

Feixa, Carles (1996). “Antropología de las edades » en Homenaje a Claudio Esteva; Frabregat (Comp.) en Ensayos de Antropología Cultural. Editorial Ariel Barcelona, España pp.319-335.

Giddens, A. (1995). Modernidad e Identidad del Yo. Ediciones Península, Madrid España.

(2003). La constitución de la Sociedad. Amarrortu/editores, Buenos Aires Argentina.

Gómez de Silva (1988). Breve diccionario etimológico de la lengua española. Fondo de Cultura Económica, México.

Mead, Margaret (1985). Educación y Cultura en Nueva Guinea. Editorial Piados España.

Oliva, Alfredo (2003). "Adolescencia en España a principios del siglo XXI" en Cultura y Educación Revista de Teoría, investigación y práctica. No. 15/4. Madrid. España pp. 370-390.

Passerni, Luisa. "La juventud, metáfora del cambio social..." en Historia de los Jóvenes II Edad contemporánea. Coord. Giovanni Levi y JeanClaude Schmitt. Santillana S.A. 1996. Taurus Madrid España. Pp.383-453.

Pérez-Rioja, J.A. (1971). Diccionario Mitológico. Editorial Porrúa; México.

Rousseau, Juan Jacobo (1979). Emilio o de la Educación. Porrúa editorial "sepan cuantos". México.

Ruiz del Campo, Emma (2001) "Adolescencia femenina y ritual: la celebración de quinceañeras en algunas comunidades en México" en Revista Espiral estudios sobre Estado y Sociedad, Enero-abril, Volumen VII. Editorial Universidad de Guadalajara, México pp. 189-222. 